\title{
Editorial
}

\section{Best Geosynthetics International Paper for 2020}

Geosynthetics International is an official journal of the International Geosynthetics Society (IGS) and serves the mandate of the society to disseminate important technical developments to its members.

We are delighted to announce results of the competition for best paper in Volume 27 (2020) based on votes cast by the Editorial Board Members. In this annual competition, the Editor-in-Chief is not eligible for this award and does not vote.

The 'Best Geosynthetics International Paper for 2020' award goes to the following paper:

van Eekelen, S. J. M. and Han, J. (2020). Geosyntheticreinforced pile-supported embankments: state of the art. Geosynthetics International, 27, No. 2, 112-141.

The following two papers were selected as runner-up and thus receive honourable mention as 'one of the best papers published in Geosynthetics International, in 2020':

Li, T.-K. and Rowe, R. K. (2020). GCL self-healing: fully penetrating hole/slit hydrated with $\mathrm{RO}$ water and $10 \mathrm{mM}$
Ca solution. Geosynthetics International, 27, No. 1, 34-47.

Ghavam-Nasiri, A., El-Zein, A., Airey, D., Rowe, R. K. and Bouazza, A. (2020). Thermal desiccation of geosynthetic clay liners under brine pond conditions. Geosynthetics International, 27, No. 6, 593-605.

We thank the members of the Editorial Board for participating in the best paper selection process and congratulate the authors of these excellent papers. Each paper reflects the high standards of the Journal and is an important contribution to our geosynthetics discipline. All IGS members have free access to these papers, as they have free access to all papers published in the Journal.

Geosynthetics International is published by Thomas Telford Ltd.

R.J. Bathurst, Editor-in-Chief Editors, E.M. Palmeira and P.J. Fox 